\title{
Status of Beliefs in Mathematics Education Among Grade Twelve Students' in Bale Zone, Ethiopia
}

\author{
Ashebir Demeke ${ }^{1} \quad$ Tesfu Belachew ${ }^{2} \quad$ Gedefa Negassa $^{2}$ \\ 1.Madda Walabu University, College of Education \& Behavioural Studies, Department of Psychology, P.o.Box \\ 247, BaleRobe, Ethiopia \\ 2.Madda Walabu University, College of Natural \& Computational Sciences, Department of Mathematics, \\ P.o.Box 247, Bale Robe, Ethiopia
}

\begin{abstract}
Studying the status of students' beliefs in mathematics education and the rationales underlying their beliefs are paramount important in classroom practices of mathematics and course development. Accordingly, the general objective of this study was to investigate the status of students' beliefs in mathematics education and the rationales underlying their beliefs. To address this objective explanatory sequential mixed method design was employed. Questionnaire, semi-structured interview and FGD were used to collect data from eight Preparatory Schools in Bale Zone. The quantitative data were analyzed mainly using mean, SD and frequency percentage. The qualitative data were analyzed using thematic narration. Consequently, this study found that an overall grade twelve students' belief in mathematics education in Bale zone was neutral. The main reasons for their neutral belief in mathematics education were might be related with their family characteristics, weak previous mathematics background, poor English language proficiency, low encouragement from existed context and poor time management. To minimize these problems it is important that the concerned bodies, such as families, schools, teachers and education professionals to work together as a team to aware students role in being successful in mathematics, to build strong mathematics knowledge early in elementary stage, and to create association between mathematics learning with practical applications.
\end{abstract}

Keywords: Beliefs, Mathematics Education, Grade Twelve Students.

DOI: $10.7176 / \mathrm{JEP} / 11-19-04$

Publication date:July $31^{\text {st }} 2020$

\section{Introduction}

Whether acknowledged or not, whether conscious or not, beliefs shape mathematical behavior (Schoenfeld, 1992). It help students to be more eager and willing to learn and to study mathematics; to use their prior knowledge to construct newer; to develop relationships and relate mathematics to the contextual situation to solve real life problems; and to facilitate the skill of problem solving and mathematical logical thinking. Beliefs also affect knowledge acquisition and interpretation, task definition and selection, interpretation of course content and comprehension monitoring by teachers (Pajares, 1992). Indeed, students' beliefs in mathematics can determine how students choose to approach a problem, which techniques will be used or avoided, how long and how hard one will work on it, and so on (Dweck, et al., 2004; Linnenbrink \& Pintrich, 2004). This in turn helps to students develop confidence in mathematics, high mathematical self-concept, and positive attitude toward mathematics which act as force for success being strength and power for students' in learning mathematics, solving problems and better mathematics achievement.

On these bases, various researches were done to verify the beliefs of students in mathematics and their impact on mathematics learning, problem solving and mathematics achievement. For instance, Randel, et al. (2000) conducted a research on attitudes, beliefs, and mathematics achievement of German and Japanese high school students. Accordingly, the researchers found that compared to the Japanese students, the German students were more likely to agree with the statement that natural ability is more important than effort, and test scores depend on one's natural ability. Also, the most frequent choice of the German students was having a good teacher; whereas for the Japanese students it was studying. Moreover, it was revealed that it was the German, not the Japanese students, who showed higher levels of concern and frustration, and expressed these through psychosomatic complaints, greater anxiety while taking tests, and more frequent feelings of stress.

Also, Suthar and Tarmizi (2010) conducted a research to verify effects of students' beliefs on mathematics and achievement of university students. What initiated the researchers for their study was that the lower performance of Malaysia students as compared to the neighboring Singapore students. According to the research results, the eighth grade students from Singapore were ranked first in mathematics among participating 41 countries while its neighbor, Malaysia was ranked $16^{\text {th }}$ and $10^{\text {th }}$ in 1999 and 2003 respectively. This raised the question that whether there is something behind about its students, teachers and/or school system that lead to Singapore's superiority over Malaysia in as far as mathematics performance is concerned. Thus, it is because of this Suthar and Tarmizi (2010) interested to investigate the possible weakness and flaw in Malaysian education system, including the students, teachers, schools and other characteristics of the students in hope of helping 
Malaysia improve its performance in mathematics globally. One of the purposes on their study was to examine the differences in students' achievement in university mathematics across a variety of characteristics pertaining to the students' beliefs about mathematics. The main conclusion of this research was that there was significant belief difference between students' majoring and non-majoring in mathematics. Mathematics major students believe that mathematics is easy to do and useful for their future career, as compare to mathematics non-majoring students. In addition, Xiao, et al. (2009) studied the Chinese high school students' mathematics belief and underlined that: As the grade increases, students perceive the abstract and logical characteristics of mathematics more and more, but they do not appreciate the widespread utility of math. Thus, they believe that math is almost completely unrelated to other subjects and everyday life. They believed that learning math was just for the university entrance examination, and people would survive without mathematics (Xiao, et al., 2009: 7).

Moreover, in a study conducted in Kenya in response to persistent low mathematics achievement at Kenya Certificate of Secondary Education Examinations to determine those factors affecting mathematics academic counseling services among secondary school students in Maara District, Kenya, it was found that secondary school students held tenaciously on the belief that mathematics was difficult and that they had low ability in the subject (Oundo, 2013). In addition, majority of the secondary school students in Maara District harbored negative feelings and beliefs about mathematics as a subject. Essentially, mathematics anxiety was reported as being prevalent among students including the high academic achievers who obtained less than the average grade in the subject. In fact, mathematics predicts success in all science subjects after students entered in higher institutions (Sadler and Tai, 2007). Also, in Ethiopia mathematics is a language for science and technology (MoE, 1994). In spite of this, in recent years much said about students' reluctance to continue with the study of mathematics, science and technology subjects beyond the compulsory years (Leder, et al., 2002; Semela, 2010; European Commission, 2007; Dieter \& Törner, 2010; Belachew, 2015). This is widely observed in Ethiopia in first year tertiary education department choice (Belachew, 2015). Still this problem is common in mathematics department of Madda Walabu University. For instance in 2015 academic year only two students chosen to join the mathematics department. Hence, this problem initiates the researchers to investigate students' beliefs in mathematics education. These may contribute greatly for students to be more eager and willing to choose, study, and being successful in mathematics.

\section{Objectives of the Study}

The general objective of this study was to study the status of grade twelve students' beliefs in mathematics education and the rationales underlying their beliefs. Accordingly, the following specific objectives are drawn in order to address the problem.

1. To describe the status of grade twelve students' beliefs in mathematics education.

2. To explain the rationales underlying grade twelve students' beliefs in mathematics education.

\section{Research Questions}

In this study, the following two research questions were addressed:

1. What is the status of grade twelve students' beliefs in mathematics education?

2. What are the rationales underlying grade twelve students' beliefs in mathematics education?

\section{Materials and Methods \\ Research Design}

In this study explanatory sequential mixed methods design was employed. It is considered explanatory because the initial quantitative data results are explained further with the qualitative data. It is considered sequential because the initial quantitative phase is followed by the qualitative. Accordingly, in phase one mathematics belief scale was applied to address the first research questions of this study. Because, based on the research questions of this study, the mathematics belief scale used to address the views of large number of participants using many items. In phase two questionnaire, semi-structured interview, and focused group discussion were applied to address the rationales underlying the status of students' belief in mathematics education depending on the quantitative results.

\section{The Study Sites}

This study was conducted in Bale Zone which is found in Oromia Regional State. The Zone capital Robe town situated at $430 \mathrm{~km}$ away from Addis Ababa to Southeast Ethiopia. Bale Zone is the largest zone of Oromia Regional State with an area of $43,690.56 \mathrm{~km}^{2}$. In the Zone there are19 preparatory schools during the study conducted. Overall, there were 2516 preparatory students in the Zone in 2016/2017 academic year. 


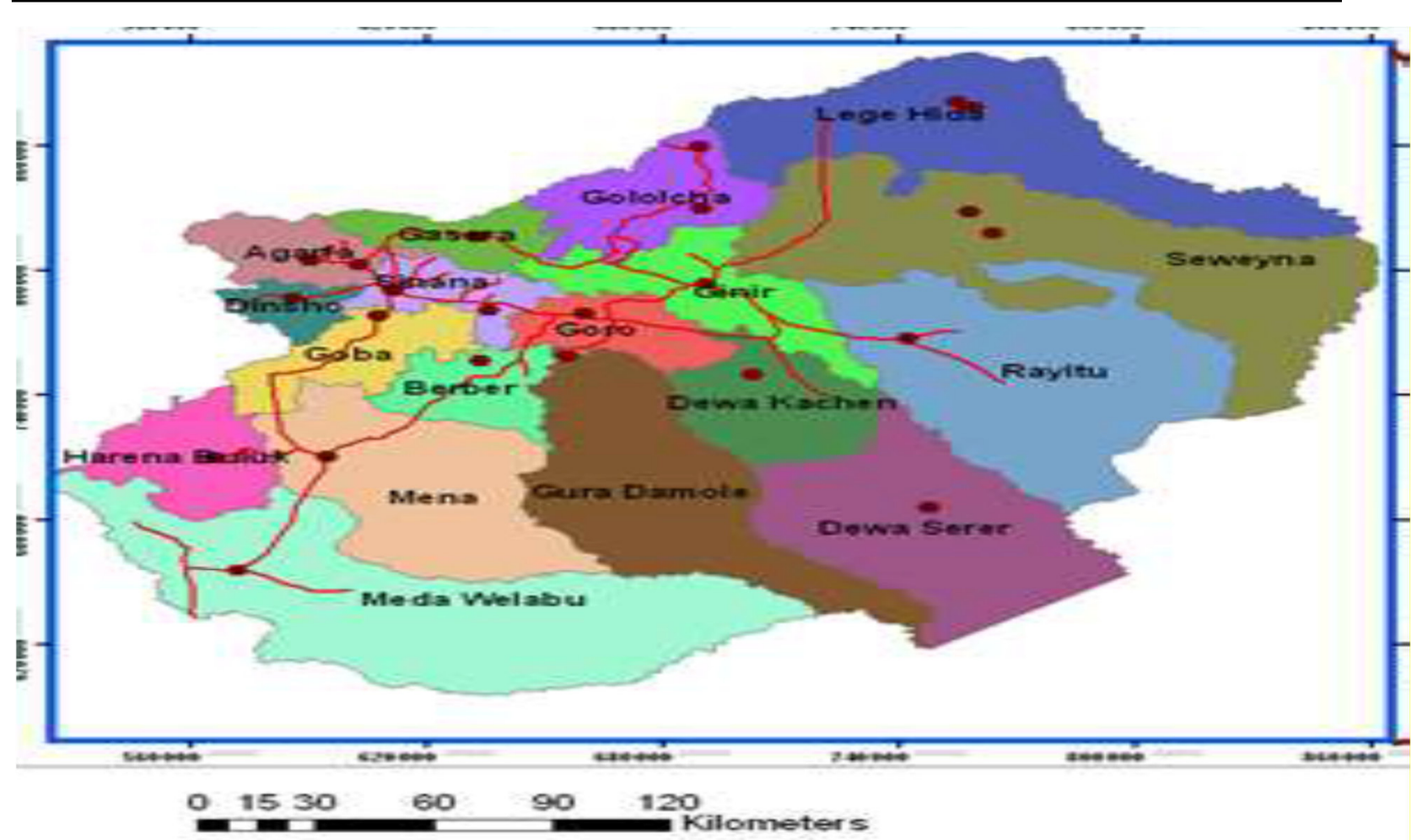

Figure 1: Bale Zone Administrative Division Source: On Line

\section{Population and Sampling}

The population of the study was all grade 12 students from government schools of Bale Zone. These include: Agarfa, Dumal, Dinsho, Gasera, Dello Sebro, Jara, Goro, Batu (Batu-terara), Obora, Ginir, Mena, Angetu, Beltu, Bidire, Chel-Chel, and Malka Mica preparatory schools. From these preparatory schools eight schools were selected using simple random sampling (lottery method). Accordingly Agarfa, DelloSebro, Batu, Ginir, Mana, Angetu, Chel-Chel and Melka Micha preparatory schools were selected from the lowlands of Bale Zone.

Table 1: Grade-12 students' data when the sample was taken and the corresponding respondents' from sampled preparatory schools

\begin{tabular}{|c|c|c|c|c|c|c|c|c|c|c|c|c|}
\hline \multirow{3}{*}{$\begin{array}{l}\text { Preparatory } \\
\text { school }\end{array}$} & \multicolumn{6}{|c|}{ Students' Data in the Sampled Schools } & \multicolumn{6}{|c|}{ Respondents' Sampled from Schools } \\
\hline & \multicolumn{3}{|c|}{ Natural science } & \multicolumn{3}{|c|}{ Social science } & \multicolumn{3}{|c|}{ Natural science } & \multicolumn{3}{|c|}{ Social science } \\
\hline & $\mathrm{M}$ & $\mathrm{F}$ & Total & M & $\mathrm{F}$ & Total & M & $\mathrm{F}$ & Total & M & $\mathrm{F}$ & Total \\
\hline Agarfa & 28 & 25 & 53 & 21 & 18 & 39 & 12 & 12 & 24 & 9 & 4 & 13 \\
\hline Angetu & 7 & 15 & 22 & 12 & 15 & 27 & 4 & 7 & 11 & 4 & 6 & 10 \\
\hline Batu & 158 & 87 & 245 & 64 & 62 & 126 & 52 & 27 & 79 & 28 & 27 & 55 \\
\hline Mena & 12 & 9 & 21 & 14 & 17 & 31 & 4 & 4 & 8 & 6 & 7 & 13 \\
\hline D/Sebro & 12 & 7 & 19 & 16 & 13 & 29 & 8 & 5 & 13 & 10 & 9 & 19 \\
\hline Ginir & 66 & 36 & 102 & 48 & 45 & 93 & 28 & 18 & 46 & 21 & 19 & 40 \\
\hline Chel-Chel & 3 & 2 & 5 & 7 & 7 & 14 & 1 & 1 & 2 & 3 & 3 & 6 \\
\hline MalkaMicha & 15 & 2 & 17 & 9 & 7 & 16 & 6 & 1 & 7 & 5 & 4 & 9 \\
\hline Total & 301 & 183 & 484 & 191 & 184 & 375 & 115 & 75 & 190 & 86 & 79 & 165 \\
\hline
\end{tabular}

Source: Respondents from sampled preparatory schools

Table 1 indicates that there were 859 (492 males and 367 females; 484 natural science and 375 social science) grade twelve students in the eight sampled preparatory schools. The sections of each selected preparatory schools were selected by using both stratified (to address male/female and natural/social students proportionally) and simple random sampling. Hence, three sections (two natural science and one social science) from grade twelve Batu preparatory school, two sections (one Natural Science and one Social Science) from grade twelve Ginir preparatory schools, and one Natural Science section from the two Natural Science sections of grade twelve Agarfa preparatory schools were selected using lottery method. For Agarfa grade twelve Social Science students the section was used as it is, since the number of Social Science section was one. Also, from Angetu, Mena, Dello Sebro, Chel-Chel, and Melka Micha preparatory schools the natural and the social science sections were considered as it is, since in each school there were only one Natural Science and one Social Sciences section. Then all students considered in the selected sections for data collection. 
The sample size of study was determined guided by Krejcie and Morgan (1970) sample size determination formula. Accordingly, the respondents of the study were 355 (201 males and 154 females) students. To collect the data using questionnaire 355 (201 males and 154 females) students were participated from the eighth grade twelve preparatory schools of Agarfa, Angetu, Batu, Mena, Dello Sebro, Ginir, Chel-Chel, and Melka Micha. The response rate was $96 \%$. Thus, the responses of 340 respondents were used for the main data analysis. The responses of 15 respondents (six males and nine females; six natural and nine social) were dropped due to incomplete responses. Also, five students for interview and seven students for focused group discussion (FGD) were considered from each preparatory schools using purposeful sampling technique.

\section{Instruments for Data Collection}

In this study mathematics belief scale, questionnaire, semi-structured interview and FGD questions were used to address the research questions. The mathematics belief scale used in this study was adapted from Belachew (2015). The scale used in pilot study has nineteen belief components with 74 items. The 19 belief components in mathematics belief scale were from the five belief categories. The first is students' beliefs about mathematics, which is represented by one belief component: students' beliefs about nature of mathematics which in turn represented by four belief items. The second is students' beliefs about mathematics learning and problem solving, which is represented by two belief components: students' beliefs about mathematics learning and students' beliefs about mathematics problem solving. Each of these belief components are represented by four belief items. The third is students' beliefs about mathematics teaching, which is represented by one belief component: students' beliefs about mathematics teaching which in turn represented by four belief items. The fourth is students' beliefs about self in mathematics education, which is represented by four belief components: students' self-efficacy beliefs, control beliefs, goal orientation beliefs, and task value beliefs about mathematics education. Each of these belief components are represented by four belief items. The fifth is students' beliefs about context support, which is represented by eleven belief components. These are students' beliefs about: mathematics as a male domain, mothers' support in mathematics education, fathers' support in mathematics education, siblings' support in mathematics education, relatives' support in mathematics education, teachers' support in mathematics education, peers support in mathematics education, non-mathematics teachers support in mathematics education, education system's support in mathematics education, mathematics text's support in mathematics education and school's support in mathematics education. Each of these belief components except mathematics text's support in mathematics education and school's support in mathematics education, which is represented by three belief items, represented by four belief items.In the scale the respondents were asked to complete on a five point Likert Scale: "Strongly agree", “Agree", "Undecided", "Disagree", and "Strongly Disagree". The response for each item was rated 1-5 so that for positive item strongly agree, agree undecided, disagree and strongly disagree worth 5, 4, 3, 2, and 1 respectively; while for negative item the rating was reversed.

Likewise, the questionnaire, the semi structured interview, and the FGD questions used in this study were adapted from Belachew (2015). The questionnaire, semi-structured interview and focused group discussion have two questions, and also the questions are the same. Moreover, besides the initial questions, participants also came up with additional points of view called follow-up interview and focused group discussion questions, spontaneously during interview and focused group discussion process, which in turn used to stimulate the participants. Regarding, trustworthiness of the qualitative data besides triangulation of information among different sources of data, member checking was employed.

\section{Validity, Reliability and Normality of Mathematics Belief Scale}

The adequate coverage of the contents related to each identified belief components, whether the items are meaningful and relevant was judged by experts. Indeed, besides getting comments of professional colleagues it became necessary to pilot the mathematics belief scale. Accordingly, the pilot-test was conducted on grade 12 students of Robe Preparatory School in December 2016. In doing so, two sections, one from natural science and one from social science, and then 45 students ( 24 males and 21 females; 28 natural science students and 17 social science students) were selected from the two sections using simple random sampling.

The reliability statistics (Cronbach's Alpha) result for students' beliefs in mathematics education revealed that 0.890; whereas for belief components it is greater than 0.7, which indicated that the mathematics belief scale and its belief components were internally consistent (reliable) (Cohen, et al., 2003). The skewness statistics for each item of the mathematics belief scale is between -1 and 1 . So, the data distribution is normal (Leech, et al., 2005). Also, for this pilot study there were 39 correctly responded observations, so greater than the numbers of the predicators (belief components). Indeed, the dependent variable, that is, students' beliefs in mathematics education is a scale level variable, which is normally distributed in the data. In addition, testing with the help of SPSS 20 the remaining assumptions (e.g. correlation between dependent variable and predicators) were satisfied. For instance, the relationship between each of the belief components and students' beliefs in mathematics education was linear as it was tested by drawing scattered plot. Moreover, in the pilot study the correlations between students' beliefs 
about non mathematics teachers' support and students' beliefs about relatives' support in mathematics education is $\mathrm{r}(39)=.937$. This high correlation among predictors indicates that it is more likely there was a problem of multicollinearity (Leech, et al., 2005; Garson, 2012). Thus, based on the rule of thumb one of these belief components were dropped; in this case, students' beliefs about relatives' support in mathematics education discarded from the regression analysis due to multicollinearity (Garson, 2012). Hence, regression analysis was performed with eighteen belief components of the pilot data to determine the contribution of each of the remaining belief components to students' beliefs in mathematics education. This was summarized in Table 2 .

Table 2:Contribution of Each Belief Components to Students' Beliefs in Mathematics Education for the Pilot Study

\begin{tabular}{lc}
\hline Belief Components & Contribution (\%) \\
\hline Students' beliefs about nature of mathematics & 3.38 \\
Students' beliefs about mathematics learning & 3.47 \\
Students' beliefs about mathematics problem solving & 5.70 \\
Students' beliefs about mathematics teaching & 4.42 \\
Students' self-efficacy beliefs & 10.70 \\
Students' control beliefs & 6.12 \\
Students' goal orientation beliefs & 7.26 \\
Students' task value beliefs & 4.78 \\
Students' beliefs about mathematics as a male domain & 2.64 \\
Students' beliefs about mothers' support & 5.23 \\
Students' beliefs about fathers' support & 7.55 \\
Students' beliefs about siblings' support & 5.60 \\
Students' beliefs about mathematics teachers' support & 4.12 \\
Students' beliefs about peers' support & 8.76 \\
Students' beliefs about non mathematics teachers' support & 1.98 \\
Students' beliefs about education system's support & 3.24 \\
Students' beliefs about mathematics text's support & 7.56 \\
Students' beliefs about school's support & 6.52 \\
Total &
\end{tabular}

According to Table 2, the belief components with less than $3 \%$ contribution to students' beliefs in mathematics education include: students' beliefs about mathematics as a male domain (2.64\%), and students' beliefs about non mathematics teachers' support (1.98). So the contributions of these belief components were low; therefore, they discarded from the mathematic belief scale. Hence, sixteen belief components were used for final data collection. Indeed, for final data collected these sixteen belief components the reliability statistics (Cronbach's Alpha) of the main study for both belief components and students' beliefs in mathematics education were greater than 0.7. This showed that the mathematics belief scale was internally reliable (Cohen, et al., 2003). Also, for mathematics belief scale and students' beliefs in mathematics education the skewness values (statistics) are between -1 and 1 . Accordingly, the data distribution is normal (Leech, et al., 2005).

\section{Method of Data Analysis}

In accordance with the objective of the study and the research questions to analyze the data frequency percentage, mean and SD were employed using SPSS version 20. Data collected through questionnaire, semi structured interview and focused group discussion were analyzed through thematic narration.

\section{Result and Discussion}

The Status of Grade Twelve Students' Beliefs in Mathematics Education

For the mathematics belief scale a five point likert scale with values from 1.0 to 5.0, the averages ranged from 1.0 to 5.0 was considered. Accordingly, students' beliefs in mathematics education can be high, or medium, or low (Norouzian, and Mehdizadeh, 2013; Mohamed and Waheed, 2011; Belachew, 2015). The high students' beliefs would be within the average range of 3.5 to 5.0 , which refers to positive beliefs ( 3.5 to 4.4 ) and strongly positive students' beliefs ( 4.5 to 5.0 ) in mathematics education. The medium students' beliefs would be within the average range of 2.5 to 3.4, which refers to neutral students' beliefs in mathematics education that is neither positive nor negative. The low students' beliefs would be within the average range of 1.0 to 2.4 , which refers to strongly negative beliefs (1.0 to 1.4) and negative students' beliefs (1.5 to 2.4) in mathematics education. Now to answer the question related to status of students' beliefs in mathematics education the mean of students' beliefs in mathematics education was obtained using SPSS (see Table 3).

Table 3: The Status of Grade Twelve Students' Beliefs in Mathematics Education

\begin{tabular}{|c|c|c|c|c|c|}
\hline Belief Variable & $\mathrm{n}$ & $\mathrm{M}$ & SD & Level & Description of level \\
\hline Students' beliefs in mathematics education & 340 & 3.2 & .4 & Medium & Neutral \\
\hline
\end{tabular}


Table 3 discloses that the mean of students' beliefs in mathematics education was 3.2. So, the status of students' beliefs in mathematics education denotes as medium level, that is, neutral, this is neither positive nor negative beliefs. The neutral status of students' beliefs in mathematics education is not positively supporting to increase students' motivation for learning, problem solving and being successful in mathematics. Indeed, it does not have positive effect on their motivation and performance. This status of students' beliefs in mathematics education cannot be seen by directly observing the individual students' beliefs; rather it must be inferred from their reflections and actions (Schuck \& Grootenboer, 2004).

This result revealed in this study is in agreement with Belachew (2015), which conducted a study in West Arsi Zone Grade Eleven students' beliefs in mathematics education and found that majority of students' revealed neutral beliefs. On other hand the result in this study is not in agreement with Kele (2014) and Oundo (2013. For example, Kele (2014) investigated high school students' beliefs and attitudes in the Solomon Island towards learning mathematics in New Zealand and conclude that students were very positive about learning mathematics; whereas, Oundo (2013) conducted a study in Kenya secondary school students found that majority of the secondary school students' harbored negative feelings and beliefs about mathematics as a subject.

Most likely, the reasons for their neutral beliefs in mathematics education are their family characteristics such as socio-economic status of parents, family's level of education and the more children in the household, family's occupation, and source of family's income. In connection with student parents socio-economic status both in the interview and focused group discussion with students uncovered that their parents are highly dependent on small farming and also socially emphasis their children to be more motivated and to spend much of their time in agriculture. In line with students' family's occupation, this study indicated that $55.9 \%$ of students' parents were famer, $26.8 \%$ of them are students whose parents are government organization employee, and $25.5 \%$ of them are students whose parents are merchant, day laborer and others. Hence, most of the students family's day to day practice is farming; and they may pressurize their children to this activity. Similarly during focused group discussion students indicated that they do not have clear understanding about the role of education in general specifically the role of mathematics in their life. They associated this with their parents and society's gloomy values of education and lack of emphasis on hard working in education. Because of that students pointed out that they have little purpose or reason for doing an activity which is also characterized by lack of a motivational style characterized by absence of perseverance and commitment.

Also, in connection with students' family income this study showed that $58.8 \%$ of family's income was from agriculture, $21.5 \%$ of family's income was from government or nongovernment organization, and 27.8 from trade, day laborer and others. This in turn influenced students to give much emphasis and spend much time to agricultural related activities and not to give attention and time for education and educational activities. Moreover, examining students' families' level of education, the study revealed that $49.7 \%$ of them are uneducated or at elementary level and only $15.9 \%$ of them are at degree level and above, so that students' families do not emphasis education in their life and do not have the culture to motivate and to support regularly their children in education. In particular, the parents of most children have no concern to motivate their student children in mathematics education.

Moreover, as revealed in the interview and focused group discussion the other reason for the neutral status of students' beliefs in mathematics education are teacher dominated classroom teaching and dependency on the teacher. In this case students believe that mathematics teachers are more responsible for their beliefs in mathematics education and they are expecting knowledge to be transmitted from the mathematics teacher, which is also considered as the source of the answer for the problems in their mathematics text. The students also explained in the focused group discussion that weak previous mathematics background, poor English language, low encouragement from existed context and poor time management contributed for their neutral beliefs in mathematics education. Furthermore, in the questionnaire and in the interview students expressed that mathematics is inhuman, that does not easily touch their feeling and does not easily inspire them to learn. They also indicated that the mathematics they have learned in the school have little application in their surrounding environment or nothing to do with real thinking. Even students indicated that in most cases they cannot give attention to the role of mathematics in physics, chemistry, and economics and they believe that mathematics is not strongly related to other subjects and unrelated to everyday life. In most cases they consider that learning mathematics is just for the university entrance examination.

However, all respondents in this research did not have neutral beliefs in mathematics education (Refer table 4).

Table 4: The Status of Students' Beliefs in Mathematics Education Based on Its Average Score

\begin{tabular}{lcccccc}
\hline Belief Variable & $\mathrm{N}$ & \multicolumn{3}{c}{ Percentage of Respondents in Each Levels } \\
\cline { 3 - 6 } & & $\begin{array}{c}\text { Strongly } \\
\text { positive }\end{array}$ & Positive & Neutral & Negative $\begin{array}{c}\text { Strongly } \\
\text { negative }\end{array}$ \\
\hline $\begin{array}{c}\text { Students' beliefs in mathematics } \\
\text { education }\end{array}$ & 340 & 0.0 & 26.5 & 51.8 & 21.8 & 0 \\
\hline
\end{tabular}

As revealed in Table 4, all students were not assigned in the same status of beliefs, that is, neutral level rather 
only $51.8 \%$ of students have neutral beliefs in mathematics education. The remaining $26.5 \%$ of the students have positive beliefs, and $21.8 \%$ of the students have negative beliefs.

\section{Conclusions and Recommendations \\ Conclusions}

The general objective of this research was to investigate the status of grade twelve students' beliefs in mathematics education and the rationales underlying their beliefs. To address the objective, mixed method research approach was employed. Questionnaire, semi-structured interview, and FGD were used as an instrument to collect data and to address the objectives. Accordingly, the status of grade twelve students' beliefs in mathematics education is neutral; this is neither positive nor negative beliefs. The neutral status of students' beliefs in mathematics education is not optimistically supporting to increase students' motivation for learning, problem solving and being successful in mathematics.

The main reasons for their neutral beliefs in mathematics education are their family characteristics such as socio-economic status of parents, family's level of education and the more children in the household, family's occupation, and source of family's income. Parents are highly dependent on farming and they encourage their children to follow their line. There is also low values of education and lack of continuous effort in education by parents of the students and societies. Students indicated that from the time they joined school family's do not make aware them the importance of academic success in general and in mathematics in particular. In addition, examining students' families' level of education, the study revealed that about half of them were uneducated or at elementary level and only $15.9 \%$ of them are at degree level and above, so that most of the students' families do not have positive regards for education in general and for mathematics in particular in their life. Astonishingly, they do not have the culture to motivate and to support regularly their children in education. Moreover, the other reasons for students' neutral beliefs in mathematics education are teacher dominated classroom teaching and dependency on the teacher. The students have also the culture to consider the teacher as the source of the answer for the problems in their mathematics text. In addition, weak previous mathematics background of students, students' problem related to second language, low encouragement from existed context and poor time management contributed for students' neutral students' beliefs in mathematics education. Furthermore, the nature of mathematics as a subject such as its inhuman nature has a share in their neutral beliefs in mathematics education in their surrounding environment.

\section{Recommendations}

In this study, the following were recommended:

\section{For Students}

It is important students to identify and clearly know their role and their responsibility in academic success in general and success in mathematics in particular and to accomplish this managing their time wisely. Also, it is good students to give emphasis that mathematics is the key in both natural and social science subjects in order to understand the concepts and secure their future career. Indeed, it is essential students to change their opinion and to belief that they can be successful in mathematics. Accordingly, it is good students to modify their work culture so that to give attention to student' centered approach and to individual effort in being successful in mathematics not only rhetorically but also in practical level.

\section{For Parents}

It is good parents not only to be parents of their student children but also to be their academic advisor. So, it is important parents to assist their student children regularly both psychologically and materially.

\section{For School}

It is good the school fulfill school characteristics such as the effect of school quality and supportive mechanism for securing quality mathematics education and to satisfy its customers need. This is by assuring that both using well qualified mathematics teachers and by making available the necessary resources that will assist students to learn as much as possible. It is also important the school to help students to develop the culture of working together and to facilitate tutorial services for students. It is also good the school to facilitate different reinforcing mechanisms to draw student to the field of peaceful academic competition.

\section{For Mathematics Teachers}

It is good mathematics teachers to be effective in their profession to produce patriots of science and technology which is a good seeds that is well equipped in mathematics knowledge.

\section{For Further Studies}

Based on the conclusions of this study, the researchers recommend further research to verify the findings of this study on other grade levels including other variables and demographic areas for better generalization.

\section{References}

Belachew T. (2015). Students' Beliefs in Mathematics Education: The Case of West Arsi Zone, Ethiopia. Doctoral 
dissertation, Addis Ababa University.

Cohen, L., Marion, L. \& Morrison, K. (2003). Research methods in education. $5^{\text {th }}$ Edition. London: Rutledge.

Dieter, M. \&Törner, G. (2010).Figures about the study of mathematics in European countries and the USA, A nontrivial research analysis. Newsletter of the European Mathematical Society, 77, 25-30.

Dweck, S. C., Good, C.,\&Mangels, A. J. (2004). Motivational Effects on Attention, Cognition, and Performance. In Dai Y. D. \& Sternberg J.R (Eds.). Motivation, Emotion, and Cognition: Integrative Perspectives on IntellectualFunctioning and Development. (Pp.41-55). Lawrence Erlbaum Associates, Inc.

European Commission. (2007). Science Education Now: A Renewed Pedagogy for the Future of Europe. Eds.: Rocard, M., Csermely, P., Jorde, D., Lenzen, D.,Walberg-Henriksson, H., Hemmo, V.; Directorate-General for Research, Science, Economy and Society, EUR Report 22845, European Commission.

Garson, G. D. (2012). Testing statistical assumptions. North Carolina: Statistical Associates Publishing.

Kele, A. (2014). An Investigation of beliefs and attitudes of high school students in the Solomon Islands towards learning mathematics (Doctoral dissertation, University of Waikato).Retrived 8/1/2015 from https://scholar.google.com/scholar?pdf.

Kerejcie R. V., \& Morgan D. W. (1970). Determing sample size for research activities. Educational and Psychological measurement, 30, 607-610.

Leech, N.L., Barrett, K.C., \& Morgan, G.A. (2005). SPSS for Intermediate Statistics; Use and Interpretation (2nd ed.). Lawrence Erlbaum Associates, Inc. New Jersey, London. Retrived June 2, 2014 from http://tip.iums.ac.ir/uploads/35_329_26_2.pdf.

Leder, G. C., Pehkonen, E., \& Tor $\ddot{n}$ er, G. (2002) (Eds.), Beliefs: A Hidden Variable in Mathematics Education? Kluwer Academic Publishers, 1-10.

Linnenbrink, A. E., \&Pintrich, R. P. (2004). Role of Affect in Cognitive Processing in Academic Contexts. In Dai, Y. D. \& Sternberg, J.R (Eds.). Motivation, Emotion, and Cognition: Integrative Perspectives on IntellectualFunctioning and Development. (Pp.57- 87).Lawrence Erlbaum Associates, Inc.

MoE.(1994). Education Sector Strategy. Addis Ababa: EMPDA.

Mohamed, L., \&Waheed, H. (2011). Secondary students' attitudes towards mathematics in a selected school of Maldives. International Journal of Humanities and Social Science, 1(15), 277-281.

Norouzian, R., \&Mehdizadeh, M. (2013).Reading Strategy Repertoires in EAP Contexts: Students and Teachers in Academic Reading Strategy Use. The International Journal of Language Learning and Applied Linguistics World, 5.

Oundo, M.B. (2013). Factors affecting mathematics academic counseling services: the secondary school counselors' perspective. International Journal of Education and Research, 1(12), 1-8

Pajares, F., \& Graham, L. (1999).Self-Efficacy, Motivation Constructs and Mathematics Performance of Entering Middle School Students. Contemporary Educational Psychology, 24, 124-139.

Randel, B., Stevenson, H. W., \&Witruk, E. (2000). Attitudes, beliefs, and mathematic achievement of German and Japanese high school students. International Journal of Behavioral Development, 24 (2): 190-198.

Sadler, P. M., \& Tai, R. H. (2007).The two high school pillars supporting college science. Science, 317(5837), 457-458.

Schoenfeld, A. H. (1992). Learning to think mathematically: Problem solving, metacognition, and sense making in mathematics. In D. A. Grouws (Ed.), Handbook of Research on Mathematics Teaching and Learning, 334369. New York: Macmillan.

Schuck, S., \&Grootenboer, P. J. (2004). Affective issues in mathematics education. In B. Perry, C. Diezmann\& G. Anthony (Eds.), Review of Mathematics Education in Australasia 2000-2003, 53-74.Flaxton, QLD: Post Pressed.

Semela, T. (2010). Who is joining physics and why? Factors influencing the choice of physics among Ethiopian university students. International Journal of Environmental \& Science Education, 5 (3): 319-340.

Suthar, V., \&Tarmizi, R., A. ( 2010). Effects of students' beliefs on mathematics and achievement of university students: regression analysis approach. Journal of Social Sciences, 6 (2), 146-152.

Xiao, C., Yu, P., \& Yan, L. (2009). Influences on affect and achievement: high school students' epistemological beliefs about mathematics. Journal of Mathematics Education, 2(2), 1-11.

\section{Acknowledgement}

We are grateful to Research, Community Engagement and Technology Transfer Vice President Office of MaddaWalabu University for granting the research. 